\title{
33. MAGNETIC PROPERTIES OF BASALTS FROM DSDP LEG 49
}

\author{
R. Day, ${ }^{1}$ S. Halgedahl, ${ }^{1}$ M. Steiner, ${ }^{2}$ K. Kobayashi, ${ }^{3}$ T. Furuta, ${ }^{3}$ T. Ishii, ${ }^{3}$ and A. Faller ${ }^{4}$
}

\section{INTRODUCTION}

Rock magnetism is the study of the fundamental magnetic properties of the magnetic minerals present in rocks. In submarine basalts the dominant carriers of the magnetic signal are titanomaghemites, which are titanomagnetites that have been oxidized to varying degrees at low temperatures. They are single phase and retain the spinel structure of the original titanomagnetite. High-temperature oxidation is generally absent in submarine basalts. Our knowledge of the magnetic properties of titanomaghemites is very limited. The most exhaustive study is that by Readman and O'Reilly (1972), who examined some of the magnetic properties of synthetic samples; but although their samples spanned the whole composition range of the titanomaghemites, their study was limited by the necessity for keeping grain size small if one is to produce single-phase oxidation products. The mean grain size in their samples was about $0.1 \mu \mathrm{m}$. So until a method is found to produce large-grain synthetic titanomaghemites, we are confined to studies of the natural grains in submarine basalts.

We have measured the magnetic properties of 99 DSDP Leg 49 basalts (Sites 407 through 413). Routine measurements of paleomagnetism were made on all samples, but the main emphasis was placed on increasing our knowledge of the rock magnetic properties.

The magnetic properties reported here are as follows:

1) Saturation magnetization $\left(J_{s}\right)$.

2) Intensity and stability of natural remanent magnetization (NRM) and isothermal remanent magnetization (IRM).

3) Hysteresis parameters, i.e., coercive force $\left(\mathrm{H}_{\mathrm{c}}\right)$, remanent coercive force $\left(\mathrm{HRC}_{\mathrm{RC}}\right)$, and the ratio $\left(\mathrm{J}_{\mathrm{RS}} / \mathrm{JS}_{\mathrm{S}}\right)$ of saturation remanence $\left(J_{R S S}\right)$ to saturation magnetization.

4) Weak field susceptibility $(\chi)$.

\section{EXPERIMENTAL METHOD}

The magnetic properties reported here were measured at the rock magnetism laboratory, University of California (Santa Barbara).

The first measurements made were routine paleomagnetism measurements on those samples that had not been measured by the shipboard party. The intensity of NRM was measured on a Schonstedt spinner magnetometer coupled to a Nova $2 / 10$ mini-computer. The samples were progressively demagnetized to at least 10 per cent of their

\footnotetext{
'University of California at Santa Barbara, U. S. A.

${ }^{2}$ California Institute of Technology, U. S. A.

${ }^{3}$ University of Tokyo, Japan.

${ }^{4}$ University of Leeds, U. K.
}

initial intensity with a Schönstedt single-axis demagnetizer. From these measurements, we obtained the initial intensity, stable inclination, and median destructive field (MDF). Acquisition of isothermal remanent magnetization was studied in selected samples from each hole before the samples were given a saturation isothermal remanent magnetization $\left(\mathrm{J}_{\mathrm{RS}}\right)$. This was then progressively demagnetized to 10 per cent of its initial value. Hysteresis loops were obtained from each sample using a vibrating sample magnetometer similar to the one described by Kobayashi and Fuller (1967). Saturation magnetization, coercive force, and the ratio of saturation remanence to saturation magnetization were read from each loop. The remanent coercive force was obtained from direct field demagnetization of $J_{R S}$. Finally weak field susceptibility, $\chi$, was measured using an AC susceptibility bridge (Fuller, 1967).

All the instruments used in this study can accommodate standard paleomagnetic cores $(2.54 \mathrm{~cm}$ diameter $\times 2.54 \mathrm{~cm}$ maximum length), and most of the samples used were approximately this size. Some samples were obtained as small 1-cm-diameter minicores or small chips of the larger standard cores. Samples significantly smaller than the standard cores are denoted by an asterisk after the sample number in Table 1.

\section{RESULTS}

Results of the magnetic measurements are listed in Table 1 in order of increasing depth in each hole. In this section we will present the data in terms of the distribution of each of the magnetic properties.

\section{Saturation Magnetization, Js}

The distribution of saturation magnetization in each hole is shown in Figure 1. In some holes there is very little variation in Js. This is most obvious in Hole 410A (18 samples), and there is some indication that the same is true for Holes 410 (6 samples), 411 (4 samples), and 413 (3 samples), although we have very few results from these holes. On the other hand, Holes 407, 408, 409, and 412A show a greater variation in saturation magnetization.

A variation in saturation magnetization could be the result of variations in composition and/or concentration. We will argue later that variation in composition, via oxidation, is the dominant cause of the variation in Js. A similar explanation has been given by Kobayashi et al. (this volume) for the variation in Curie temperatures and optical properties. In anticipation of later discussions, we have distinguished between the low-coercivity samples $(\mathrm{Hc}<$ $100 \mathrm{Oe})$ and the high-coercivity samples $(\mathrm{Hc}>100 \mathrm{Oe})$ on the histograms. The low-coercivity samples have the larger Js values. Johnston (1978) has found a similar relationship between MDF and Js. 
TABLE 1

Magnetic Properties of DSDP Leg 49 Basalts

\begin{tabular}{|c|c|c|c|c|c|c|c|c|c|c|c|c|c|}
\hline $\begin{array}{c}\text { Sample } \\
\text { (Interval in } \mathrm{cm} \text { ) }\end{array}$ & Depth $^{(a)}$ & $\mathrm{J}_{\mathrm{N}}{ }^{(\mathrm{b})}$ & $I^{(c)}$ & $\operatorname{MDF}(1)^{(d)}$ & ${ }_{\mathrm{RS}}{ }^{(\mathrm{e})}$ & $\operatorname{MDF}(2)^{(f)}$ & $\mathrm{J}_{\mathrm{S}}{ }^{(\mathrm{g})}$ & ${ }^{\mathrm{J}} \mathrm{RS} / \mathrm{J}_{\mathrm{S}}$ & $\mathrm{H}_{\mathrm{C}}{ }^{(\mathrm{h})}$ & $\mathrm{H}_{\mathrm{RC}}{ }^{(\mathrm{i})}$ & $\mathrm{H}_{\mathrm{RC} / \mathrm{H}_{\mathrm{C}}}$ & $x^{(j)}$ & $\mathrm{Q}^{(\mathrm{k})}$ \\
\hline \multicolumn{14}{|l|}{ Hole 407} \\
\hline $36-2,91-93$ & 331.4 & 3.50 & 73 & - & 0.385 & 50 & 3.50 & 0.11 & 41 & 95 & 2.32 & 3.43 & 2.0 \\
\hline $36-2,120-122$ & 331.7 & 29.5 & 64 & 30 & 0.367 & 50 & 3.67 & 0.10 & 34 & 85 & 2.50 & 3.53 & 16.1 \\
\hline $36-3,56-58$ & 332.6 & 3.25 & 66 & 25 & 0.319 & 44 & 3.19 & 0.10 & 30 & 65 & 2.17 & 3.71 & 1.7 \\
\hline $36-3,140-142$ & 333.4 & 9.03 & 72 & 85 & 0.432 & 54 & 2.88 & 0.15 & 50 & 94 & 1.88 & 3.19 & 5.4 \\
\hline $37-1,140-142$ & 339.9 & 2.68 & -70 & - & 0.437 & 55 & 2.82 & 0.16 & 45 & 80 & 1.78 & 3.42 & 1.5 \\
\hline $38-3,56-58$ & 351.5 & 4.30 & -74 & - & 0.656 & 61 & 2.85 & 0.23 & 60 & 103 & 1.72 & 2.33 & 3.5 \\
\hline $39-2,23-25$ & 359.2 & 6.36 & +68 & 45 & 0.696 & 70 & 2.78 & 0.25 & 72 & 109 & 1.50 & 1.93 & 6.3 \\
\hline $39-3,25-27$ & 360.8 & 4.40 & -70 & 140 & 0.487 & 98 & 3.04 & 0.16 & 46 & 98 & 2.13 & 2.94 & 2.9 \\
\hline $39-3,42-44 *$ & 360.9 & 2.60 & -79 & - & 0.540 & - & 2.71 & 0.20 & 62 & 124 & 2.00 & 1.65 & 3.0 \\
\hline $39-3,126-128$ & 361.8 & 1.39 & -68 & 185 & 0.508 & 49 & 3.17 & 0.16 & 53 & 90 & 1.70 & 3.07 & 0.9 \\
\hline $39-3,140-142$ & 361.9 & 2.60 & -66 & - & 0.540 & 54 & 3.38 & 0.16 & 56 & 96 & 1.71 & 2.64 & 1.9 \\
\hline $41-1,100-102$ & 377.5 & 4.30 & -42 & - & 1.04 & 200 & 1.82 & 0.57 & 197 & 250 & 1.27 & 0.694 & 11.9 \\
\hline $44-1,68-70$ & 424.7 & 18.5 & -43 & - & 0.851 & 127 & 1.93 & 0.44 & 141 & 197 & 1.40 & 0.917 & 39 \\
\hline $44-1,80-82$ & 424.8 & 26.0 & -43 & 125 & 0.851 & 90 & 2.24 & 0.38 & 118 & 164 & 1.39 & 1.21 & 41 \\
\hline $45-1,90-95^{*}$ & 434.6 & 7.06 & -62 & 183 & 0.576 & 55 & 2.22 & 0.26 & 71 & 90 & 1.27 & 1.63 & 8.3 \\
\hline $45-4,58-60$ & 438.6 & 15.6 & -57 & 450 & 0.560 & 325 & 2.80 & 0.20 & 73 & 110 & 1.51 & 2.02 & 15 \\
\hline $46-1,107-109 *$ & 444.1 & 1.83 & -60 & 425 & 0.159 & 327 & 0.252 & 0.63 & 253 & 380 & 1.50 & 0.225 & 16 \\
\hline $46-2,59-61$ & 445.1 & 6.40 & -54 & 30 & 0.479 & 50 & 3.19 & 0.15 & 57 & 105 & 1.84 & 1.83 & 6.7 \\
\hline $47-1,116-118$ & 453.7 & 1.47 & -60 & 228 & 0.160 & 218 & 0.285 & 0.56 & 183 & 271 & 1.48 & 0.261 & 10.8 \\
\hline $47-2,88-90^{*}$ & 454.9 & 1.30 & -54 & - & 0.252 & - & 0.458 & 0.55 & 287 & 393 & 1.37 & 0.240 & 10.4 \\
\hline $47-3,64-68$ & 456.1 & 12.9 & -50 & 145 & 0.581 & 69 & 3.06 & 0.19 & 62 & 116 & 1.87 & 2.51 & 9.9 \\
\hline \multicolumn{14}{|l|}{ Hole 408} \\
\hline $36-1,93-95$ & 333.4 & 0.97 & 60 & 293 & 0.188 & 165 & 0.482 & 0.39 & 134 & 236 & 1.75 & 0.555 & 3.4 \\
\hline $36-3,41-43$ & 335.9 & 2.11 & 52 & - & 0.324 & 200 & 0.568 & 0.57 & 211 & 278 & 1.32 & 0.236 & 17 \\
\hline $36-4,37-40$ & 337.4 & 1.00 & 64 & - & 0.311 & 208 & 0.676 & 0.46 & 186 & 263 & 1.42 & 0.546 & 3.5 \\
\hline $36-4,118-120$ & 338.2 & 0.59 & 63 & 555 & 0.277 & 290 & 0.433 & 0.64 & 292 & 365 & 1.25 & 0.210 & 5.4 \\
\hline $37-1,13-15$ & 342.2 & 1.00 & 61 & - & 0.165 & 215 & 0.294 & 0.56 & 183 & 260 & 1.42 & 0.281 & 6.8 \\
\hline $37-3,43-45$ & 345.4 & 10.1 & 83 & 134 & 0.437 & 82 & 2.185 & 0.20 & 71 & 120 & 1.69 & 2.02 & 9.6 \\
\hline $38-3,119-124$ & 355.7 & 8.48 & 80 & 70 & 0.354 & 55 & 2.36 & 0.15 & 59 & 115 & 1.95 & 2.14 & 7.6 \\
\hline \multicolumn{14}{|l|}{ Hole 408} \\
\hline $7-7,48-50$ & 81.5 & - & - & - & 0.447 & 46 & 2.45 & 0.18 & 45 & 95 & 2.11 & 2.23 & - \\
\hline $9-3,130-132$ & 95.3 & 4.51 & -72 & 80 & 0.225 & 35 & 2.25 & 0.10 & 35 & 76 & 2.17 & 2.95 & 2.9 \\
\hline $10-1,10-12 *$ & 100.6 & 2.20 & -74 & - & 0.163 & - & 1.79 & 0.09 & 28 & 73 & 2.61 & 3.13 & 1.4 \\
\hline $10-2,138-140$ & 103.4 & 2.72 & -68 & 800 & 0.344 & 500 & 0.573 & 0.60 & 363 & 485 & 1.34 & 0.253 & 21 \\
\hline $10-7,6-8$ & 109.6 & 7.21 & -65 & 171 & 0.316 & 45 & 2.11 & 0.15 & 45 & 85 & 1.89 & 3.16 & 4.4 \\
\hline $11-1,54-56$ & 110.6 & 6.59 & -65 & 120 & 0.535 & 100 & 1.84 & 0.29 & 113 & 163 & 1.45 & 1.20 & 10.6 \\
\hline $11-4,36-38$ & 114.9 & 4.10 & -67 & - & 0.285 & 35 & 2.85 & 0.10 & 38 & 80 & 2.11 & 2.60 & 3.0 \\
\hline $13-3,37-40$ & 132.4 & 7.79 & -47 & 255 & 0.428 & 328 & 0.75 & 0.57 & 276 & 376 & 1.36 & 0.361 & 41 \\
\hline $15-1,26-28$ & 148.3 & 6.30 & -60 & - & 0.519 & 225 & 0.98 & 0.53 & 233 & 340 & 1.46 & 0.406 & 30 \\
\hline $15-2,62-64$ & 150.1 & 10.1 & -61 & 275 & 0.729 & 195 & 1.55 & 0.47 & 169 & 275 & 1.63 & 0.555 & 35 \\
\hline $16-1,89-92$ & 158.4 & 1.73 & -64 & 775 & 0.397 & 185 & 0.72 & 0.55 & 169 & 283 & 1.67 & 0.249 & 13 \\
\hline $17-1,36-38$ & 167.4 & 2.60 & -61 & - & 0.485 & 143 & 1.10 & 0.44 & 141 & 215 & 1.52 & 0.458 & 11 \\
\hline $18-3,104-106$ & 180.6 & 8.35 & -70 & 150 & 0.457 & 115 & 1.04 & 0.43 & 113 & 180 & 1.60 & 0.381 & 42 \\
\hline $18-4,20-23$ & 181.2 & 7.10 & -61 & - & 0.386 & 125 & 0.88 & 0.44 & 141 & 170 & 1.21 & 0.317 & 43 \\
\hline $22-1,53-57^{*}$ & 215.1 & 3.10 & -66 & - & 0.281 & - & 0.662 & 0.50 & 160 & 243 & 1.52 & 0.41 & 15 \\
\hline $23-2,34-35$ & 225.9 & 3.41 & -53 & 172 & 0.485 & 165 & 1.10 & 0.44 & 140 & 234 & 1.67 & 0.423 & 16 \\
\hline $24-1,142-148^{*}$ & 235.0 & 12.2 & -55 & - & 0.748 & - & 4.16 & 0.18 & 107 & 245 & 2.29 & 4.45 & 5.3 \\
\hline $24-2,45-47$ & 235.5 & 2.43 & -59 & 313 & 0.577 & 178 & 1.28 & 0.45 & 169 & 285 & 1.68 & 0.75 & 6.2 \\
\hline $24-4,88-93$ & 238.9 & 3.30 & -62 & - & 0.247 & - & 2.25 & 0.11 & 31 & 62 & 2.00 & 3.84 & 1.7 \\
\hline $24-5,80-90$ & 240.4 & 7.19 & -63 & 170 & 0.414 & 62 & 2.07 & 0.20 & 57 & 115 & 2.03 & 2.56 & 5.4 \\
\hline $24-6,65-71$ & 241.7 & 3.87 & -61 & 48 & 0.283 & 37 & 2.57 & 0.11 & 34 & 84 & 2.49 & 3.23 & 2.3 \\
\hline $25-3,84-86$ & 246.9 & 1.69 & -64 & 605 & 0.339 & 347 & 0.574 & 0.59 & 290 & 367 & 1.27 & 0.201 & 16 \\
\hline $28-1,39-42$ & 271.9 & 7.50 & -70 & - & 0.418 & 226 & 1.20 & 0.50 & 197 & 283 & 1.44 & 0.409 & 35 \\
\hline $31-1,116-118$ & 301.2 & 3.06 & -58 & 425 & 0.376 & 250 & 0.737 & 0.51 & 197 & 280 & 1.42 & 0.321 & 18 \\
\hline \multicolumn{14}{|l|}{ Hole 410} \\
\hline $38-1,20-22$ & 349.7 & 3.34 & 26 & - & 0.318 & - & 0.815 & 0.39 & 197 & 314 & 1.59 & 0.704 & 10.1 \\
\hline $39-1,76-78$ & 359.8 & 4.50 & -2 & 230 & 0.329 & 265 & 0.715 & 0.46 & 225 & 316 & 1.40 & 0.361 & 27 \\
\hline $39-3,78-80$ & 362.8 & 9.28 & 59 & 220 & 0.281 & 107 & 0.878 & 0.32 & 113 & 195 & 1.73 & 0.416 & 47 \\
\hline $39-5,103-105$ & 366.0 & 11.4 & 30 & 350 & 0.281 & 213 & 0.703 & 0.40 & 169 & 316 & 1.87 & 0.447 & 54 \\
\hline $39-6,10-12$ & 366.6 & 11.4 & 44 & 326 & 0.237 & 239 & 0.593 & 0.40 & 197 & 327 & 1.66 & 0.515 & 47 \\
\hline $40-1,58-60$ & 368.6 & 10.8 & 46 & - & 0.256 & - & 0.522 & 0.49 & 253 & 386 & 1.53 & 0.530 & 43 \\
\hline
\end{tabular}


TABLE 1 - Continued

\begin{tabular}{|c|c|c|c|c|c|c|c|c|c|c|c|c|c|}
\hline $\begin{array}{c}\text { Sample } \\
\text { (Interval in } \mathrm{cm} \text { ) }\end{array}$ & $\operatorname{Depth}^{(a)}$ & $\mathrm{J}_{\mathrm{N}}{ }^{(\mathrm{b})}$ & $\mathrm{I}^{(\mathrm{c})}$ & $\operatorname{MDF}(1)^{(d)}$ & $\mathbf{J}_{\mathrm{RS}}{ }^{(\mathrm{e})}$ & $\operatorname{MDF}(2)^{(f)}$ & $\mathrm{J}_{\mathrm{S}}{ }^{(\mathrm{g})}$ & ${ }^{\mathrm{J}} \mathrm{RS}_{/ \mathrm{J}_{\mathrm{S}}}$ & $\mathrm{H}_{\mathrm{C}}(\mathrm{h})$ & $\mathrm{H}_{\mathrm{RC}}{ }^{(\mathrm{i})}$ & $\mathrm{H}_{\mathrm{RC}} / \mathrm{H}_{\mathrm{C}}$ & $x^{(j)}$ & $\mathrm{Q}^{(\mathrm{k})}$ \\
\hline \multicolumn{14}{|l|}{ Hole 410A } \\
\hline $1-7,21-24$ & 334.2 & 2.35 & 49 & 445 & 0.278 & 542 & 0.463 & 0.60 & 422 & 622 & 1.47 & 0.225 & 22 \\
\hline $2-1,68-70$ & 335.2 & 3.38 & 35 & - & 0.364 & - & 0.552 & 0.66 & 366 & 466 & 1.27 & 0.215 & 33 \\
\hline $2-3,87-90$ & 338.4 & 2.28 & 43 & - & 0.256 & 471 & 0.457 & 0.56 & 338 & 577 & 1.71 & 0.311 & 16 \\
\hline $2-4,20-22$ & 339.2 & 2.67 & 30 & 520 & 0.388 & 385 & 0.626 & 0.62 & 323 & 454 & 1.41 & 0.298 & 19 \\
\hline $2-4,37-40$ & 339.4 & 4.83 & 22 & 470 & 0.426 & - & 0.761 & 0.56 & 282 & 370 & 1.31 & 0.321 & 32 \\
\hline $2-5,12 \quad *$ & 340.6 & - & - & - & 0.125 & 583 & 0.284 & 0.44 & 211 & 650 & 3.08 & 0.531 & - \\
\hline $3-2,111-113$ & 346.6 & 1.67 & 15 & 265 & 0.201 & 357 & 0.379 & 0.53 & 281 & 412 & 1.47 & 0.205 & 17 \\
\hline $3-3,117-119$ & 348.2 & 2.80 & 14 & 335 & 0.316 & 174 & 0.810 & 0.39 & 166 & 265 & 1.60 & 0.443 & 13 \\
\hline $4-2,87-93$ & 355.9 & 3.63 & 15 & 155 & 0.315 & 195 & 0.829 & 0.38 & 169 & 260 & 1.54 & 0.519 & 15 \\
\hline $4-3,127-130$ & 357.8 & 2.21 & 16 & 455 & 0.264 & 250 & 0.539 & 0.49 & 233 & 352 & 1.51 & 0.314 & 15 \\
\hline $4-4,33-35$ & 358.3 & 1.97 & 15 & 475 & 0.272 & 244 & 0.567 & 0.48 & 225 & 355 & 1.58 & 0.310 & 13.5 \\
\hline $4-4,43-45$ & 358.4 & 3.14 & 14 & - & 0.325 & 255 & 0.722 & 0.45 & 217 & 333 & 1.53 & 0.427 & 16 \\
\hline $5-1,69-76$ & 363.7 & 6.47 & 1 & 295 & 0.330 & 375 & 0.623 & 0.53 & 295 & 408 & 1.38 & 0.344 & 40 \\
\hline $5-4,6-8$ & 367.6 & 4.67 & 20 & 505 & 0.413 & 240 & 0.712 & 0.58 & 239 & 346 & 1.45 & 0.297 & 33 \\
\hline $5-4, ?$ & $?$ & - & - & - & 0.396 & 279 & 0.733 & 0.54 & 253 & 367 & 1.45 & 0.304 & - \\
\hline $5-4,95-106$ & 368.5 & 7.99 & 18 & 409 & 0.407 & 550 & 0.599 & 0.68 & 506 & 655 & 1.29 & 0.193 & 88 \\
\hline $6-1,8-16$ & 372.6 & 2.66 & 18 & 176 & 0.236 & 287 & 0.482 & 0.49 & 239 & 356 & 1.49 & 0.353 & 16 \\
\hline $6-1,38-41$ & 372.9 & 2.51 & 23 & 673 & 0.281 & - & 0.476 & 0.59 & 506 & 569 & 1.12 & 0.211 & 35 \\
\hline \multicolumn{14}{|l|}{ Hole 411} \\
\hline $1-1,78-81$ & 74.8 & 3.83 & -53 & 61 & 0.238 & 65 & 1.08 & 0.22 & 68 & 113 & 1.67 & 1.23 & 6.9 \\
\hline $2-1,90$ * & 82.4 & 5.35 & -52 & 127 & - & - & . & 0.21 & 49 & & & 1.44 & 8.3 \\
\hline $2-2,6-9$ & 83.1 & 6.78 & -50 & 77 & 0.287 & 79 & 1.15 & 0.25 & 87 & 138 & 1.59 & 1.10 & 14 \\
\hline $5-1,15 \quad *$ & $110.2-$ & $16.3 ?$ & $27 ?$ & 57 & 0.515 & 171 & 1.14 & 0.45 & 158 & 251 & 1.59 & 0.487 & $74 ?$ \\
\hline $5-1,21-23 *$ & $110.2^{+}$ & 1.82 & -68 & - & 0.486 & 152 & 1.22 & 0.40 & 141 & 247 & 1.75 & 0.344 & 11.8 \\
\hline \multicolumn{14}{|l|}{ Hole 412A } \\
\hline $1-1,29-30 *$ & 156.3 & 7.99 & 62 & - & 0.232 & 40 & 1.66 & 0.14 & 38 & 85 & 2.24 & - & - \\
\hline $2-1,52-54 *$ & 166.0 & - & - & - & 0.520 & 193 & 1.18 & 0.44 & 197 & 280 & 1.42 & 0.657 & - \\
\hline $2-2,35-37$ & 167.4 & 1.99 & -43 & 24 & 0.147 & 30 & 1.84 & 0.08 & 31 & 75 & 2.42 & 2.36 & 1.9 \\
\hline $3-2,35-37$ & 176.9 & 5.18 & -43 & 42 & 0.137 & 40 & 1.71 & 0.08 & 27 & 77 & 2.85 & 2.59 & 4.4 \\
\hline $7-1,52 \quad *$ & 213.5 & 5.00 & -46 & 325 & 0.499 & 150 & 1.28 & 0.39 & 155 & 234 & 1.51 & 0.583 & 19 \\
\hline $7-2,60-62$ & 215.1 & 3.28 & -55 & 115 & 0.410 & 115 & 2.16 & 0.19 & 90 & 182 & 2.02 & 1.31 & 5.6 \\
\hline $9-1,48-50$ & 232.5 & 5.88 & -50 & 95 & 0.392 & 66 & 1.40 & 0.28 & 65 & 131 & 2.01 & 1.48 & 8.8 \\
\hline $10-1,39-41$ & 241.9 & 2.87 & -67 & - & 0.226 & - & 2.51 & 0.09 & 31 & 65 & 2.10 & 2.77 & 2.3 \\
\hline $11-2,50$ & 253.0 & 1.70 & -63 & 86 & 0.141 & 37 & 1.76 & 0.08 & 28 & 80 & 2.86 & 2.29 & 1.6 \\
\hline $11-3,69-71$ & 254.7 & 3.72 & -67 & 145 & 0.264 & 55 & 1.76 & 0.15 & 55 & 115 & 2.10 & 1.88 & 4.4 \\
\hline $14-1,12-14$ & 279.6 & 2.36 & -53 & - & 0.149 & - & 1.49 & 0.10 & 23 & 65 & 2.83 & 3.44 & 1.5 \\
\hline $14-1,45 \quad *$ & 279.9 & 15.9 & -50 & 135 & 0.300 & 77 & 2.31 & 0.13 & 62 & 140 & 2.26 & 1.81 & 20 \\
\hline $14-2,99-101$ & 282.0 & 1.95 & -50 & 27 & 0.109 & 27 & 1.82 & 0.06 & 17 & 70 & 4.12 & - & - \\
\hline $14-5,30-32$ & 285.8 & 0.794 & -70 & 65 & 0.111 & 30 & 3.70 & 0.03 & 18 & 75 & 4.17 & 2.12 & 83 \\
\hline \multicolumn{14}{|l|}{ Hole 413} \\
\hline $1-2,66 \quad *$ & 110.6 & 16.6 & -54 & 93 & 0.351 & 111 & 1.03 & 0.34 & 98 & 170 & 1.73 & 0.519 & 71 \\
\hline $1-2,64-67$ & 110.6 & 7.9 & -58 & 110 & 0.319 & 93 & 0.89 & 0.36 & 110 & 166 & 1.51 & 0.439 & 40 \\
\hline $1-2,100$ * & 111 & 12.3 & -59 & - & 0.410 & 126 & 1.22 & 0.34 & 113 & 195 & 1.73 & 0.616 & 44 \\
\hline $1-2, ?$ & $?$ & 10.9 & - & 410 & - & - & - & 0.41 & 149 & - & - & 0.467 & 52 \\
\hline
\end{tabular}

a Depth (m).

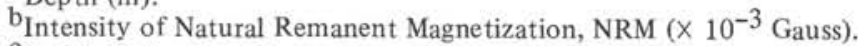

${ }^{\mathrm{c}}$ Stable Inclination (degrees).

dMedian Destructive field of NRM (Oe).

e Saturation Remanence (Gauss).

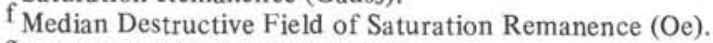

gaturation Magnetization (Gauss).

${ }^{\mathrm{h}}$ Coercive Force (Oe).

${ }_{\mathrm{j}}^{\mathrm{i}}$ Remanent Coercive Force (Oe).

$\mathrm{j}$ Initial Susceptibility ( $\times 10^{-3}$ Gauss/Oe).

$\mathrm{k}_{\text {Koenigsberger ratio. }}$ 
R. DAY ET AL.
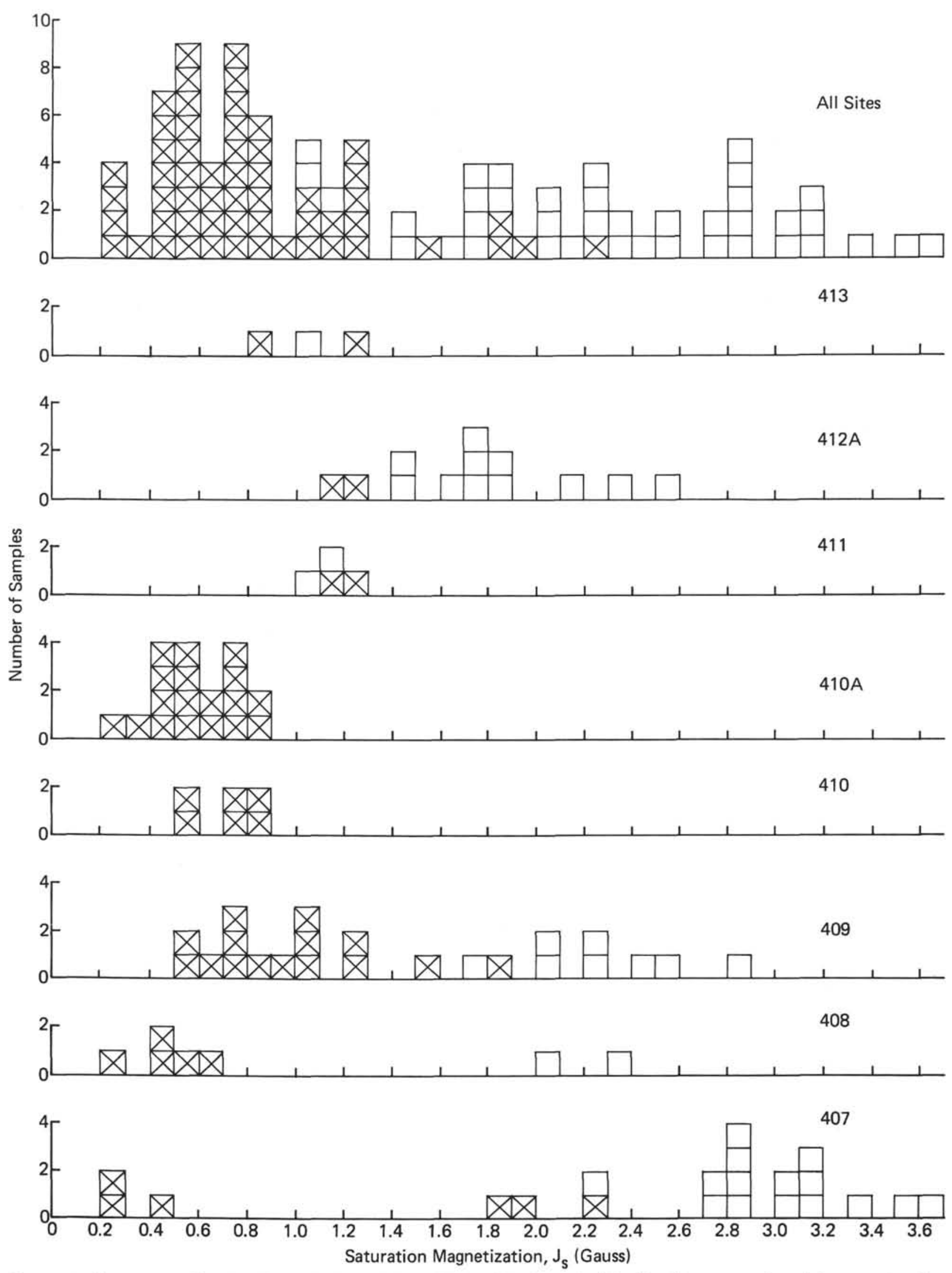

Figure 1. Histograms showing the variation of $J_{S}$ in Holes 407 through 413.X indicates samples with a coercive force greater than $100 \mathrm{Oe}$ (see text). 


\section{Saturation Remanence, JRs, and JRs/Js}

One might expect to find a greater variation in $\mathrm{JRS}_{\mathrm{R}}$ than $\mathrm{Js}$, because $J_{R s}$ is dependent on grain size and shape, as well as on composition and concentration. This is not the case here; the samples with the lower $\mathrm{J}_{\mathrm{RS}} / \mathrm{J}_{\mathrm{s}}$ values have the larger $\mathrm{J}_{\mathrm{s}}$ values, and this tends to tighten the distribution of $J_{R S}$ (Table 1). The ratio $J_{R S} / J_{s}$ is a useful magnetic parameter because it is independent of concentration. Figure 2 shows the distribution of $\mathrm{J}_{\mathrm{RS}} / \mathrm{Js}$. Hole $412 \mathrm{~A}$ is dominated by low $\mathrm{J}_{\mathrm{RS}} / \mathrm{JS}_{\mathrm{S}}$ values, whereas Hole 410 and Hole $410 \mathrm{~A}$ samples have only high $\mathrm{JRS} / \mathrm{Js}$ values. In Holes 407,408 , and 409, there are both high and low values. The whole sample set histogram indicates that there is a bimodal distribution of $\mathrm{J}_{\mathrm{RS}} / \mathrm{Js}$ values. When the samples are divided on the basis of coercivity (100 Oe breakpoint), the indication of a bimodal distribution becomes stronger, and the larger $\mathrm{J}_{\mathrm{RS}} / \mathrm{J}_{\mathrm{S}}$ values correlate with the higher coercivities. $\mathrm{J}_{\mathrm{RS}} / \mathrm{JS}_{\mathrm{s}}$ gives a good indication of the domain state of the magnetic minerals. Values around 0.5 or more are expected for single-domain (SD) grains, whereas multidomain (MD) grains should have values below about 0.1 . Pseudo-single-domain (PSD) grains have values between 0.1 and 0.5 . Most of our samples therefore contain SD and PSD grains. This corresponds to grain sizes less than about 30 or $40 \mu \mathrm{m}$ for titanomagnetites of composition $0.4 \mathrm{Fe}_{3} \mathrm{O}_{4}-0.6 \mathrm{Fe}_{2} \mathrm{TiO}_{4}$ (Day et al., 1977). This estimate agrees with the visual estimates given in the next chapter.

\section{Coercive Force, Hc, Remanent Coercive Force, Hrc, and Median Destructive Field, MDF}

Figure 3 shows the distribution obtained for the bulk coercive force $(\mathrm{Hc})$. Again we see different behavior in each hole; all holes show a wide range of bulk coercivities. In Hole $412 \mathrm{~A}$, the bulk coercivities are low; 12 of the 14 samples measured have Hc $<100$ Oe. In contrast, in Hole $410 \mathrm{~A}$ all 18 samples have high coercivities ( $>160 \mathrm{Oe}$ ). Holes 407, 408, and 409 again show the greatest variation in $\mathrm{Hc}$, although in Hole 407 there is a definite bias toward low Hc. Coercive force is not as good an indicator of domain state and magnetic grain size as $\mathrm{JRS}_{\mathrm{RS}} \mathrm{Js}$, because we have to consider the origin of coercivity. After examining all the magnetic data, however, we feel that there is a natural (although somewhat arbitrary) break at about $\mathrm{Hc}=$ 100 Oe. This break does not necessarily coincide with the SD-PSD or PSD-MD transition size, but as we will see later, it is related to the oxidation state of the magnetic grains.

The distribution of remanent coercive force $\left(\mathrm{H}_{\mathrm{RC}}\right)$ is not shown, because it is not too different from that of $\mathrm{Hc}$, but the ratio $\mathrm{HRC} / \mathrm{Hc}$ is shown (Figure 4) for the whole sample set. Theory (Stoner and Wohlfarth, 1948) predicts that in the limiting case of a random assemblage of identical non-interacting uniaxial SD grains, $\mathrm{HRc}_{\mathrm{Rc}} / \mathrm{Hc}=1.09$. In practice, values less than about 1.4 are obtained for SD titanomagnetites (Day et al., 1977). As the grain size increases through the PSD range, $\mathrm{HRC} / \mathrm{Hc}$ increases from about 1.4 to 3 or so. It is not possible to calculate $\mathrm{HRc} / \mathrm{Hc}$ for the PSD-MD transition, but experimentally derived values of 3 to 4 are found for this transition (Parry, 1965; Day et al., 1977). With these estimates in mind, we can now use $\mathrm{HRc} / \mathrm{Hc}$ to obtain another estimate of the magnetic grain sizes in our samples. Again we find that most of our samples contain SD and small PSD grains, and it is these samples that have the high Hc values (Figure 4).

In the absence of measurements of $\mathrm{Hc}_{\mathrm{c}}$ and $\mathrm{H}_{\mathrm{RC}}$, the mean destructive field (MDF) has commonly been used to estimate the coercivity distribution. We have listed the MDF's of our samples in Table 1. MDF(1) is the mean destructive field from the NRM demagnetization curve, and MDF(2) is from the IsRM demagnetization curve. Derivations of coercivity spectra from MDF(1) values must be made cautiously, since reversed samples have in general higher MDF's because of the presence of a normal secondary component. $\operatorname{MDF}(2)$ will give a better estimate of the coercivity.

\section{Weak Field Susceptibility, $\chi$}

The distribution of weak-field susceptibility is shown in Figure 5. A logarithmic scale has been used on the abscissa for convenience in plotting. We do not, however, want to suggest that this is necessarily of physical significance. Figure 5 shows that there is a relationship between $\chi$ and Hc. Low susceptibility is observed for samples with a high coercive force.

\section{Intensity of Natural Remanent Magnetization, $\mathrm{JN}_{\mathrm{N}}$ and the Koenigsberger Ratios, $\mathbf{Q}(=\mathrm{JN} / \chi \mathbf{H})$}

The intensity of natural remanent magnetization is shown in Figure 6. We do not find a correlation here between $\mathbf{J}_{\mathrm{N}}$ and $\mathrm{Hc}$, and the distributions of $\mathrm{J}_{\mathrm{N}}$ for high $\mathrm{Hc}_{\mathrm{c}}$ samples and low Hc samples are similar. The Koenigsberger ratio, Q (Figure 7), does correlate with Hc; the highest Q values are observed for the high coercivity samples. This correlation is therefore the result of the strong correlation between $\chi$ and Hc.

\section{DISCUSSION}

The results given in Table 1 and Figures 1 through 7 indicate that there are two kinds of magnetic behavior in these submarine basalts. Some samples, such as those from Hole 410A, are typical of SD and small PSD grains; that is, $\mathrm{J}_{\mathrm{RS}} / \mathrm{Js}$ is close to $0.5, \mathrm{HRC} / \mathrm{Hc}$ is low, the initial susceptibility is low, and the NRM and the saturation remanence are both stable to A.F. demagnetization. Other samples, for instance most of those from Hole 412A, exhibit soft magnetic properties indicating large PSD and MD grains. In Figure 8, we have plotted $\mathrm{JRS}_{\mathrm{RS}} / \mathrm{JS}_{\mathrm{S}}$ against $\mathrm{HRC}_{\mathrm{RC}} / \mathrm{Hc}$ to show how the submarine basalts compare with sized synthetic titanomagnetites. It is obvious from Figure 8 that SD and PSD grains are dominant in most of the samples.

We have measured the Curie temperature of 28 of the 99 samples (see Kobayashi et al., this volume). The magnetic properties of these samples are listed in Table 2, along with the thermomagnetic data from the next chapter (Kobayashi et al., this volume).

In Table 2, the samples have been divided according to the type of thermomagnetic curve. The first 13 samples have reversible thermomagnetic curves, and the rest (15 samples) have irreversible curves. The difference between the magnetic properties in these two groups is striking. The reversible group contains the samples that are magnetically soft; the irreversible group contains the samples that are 

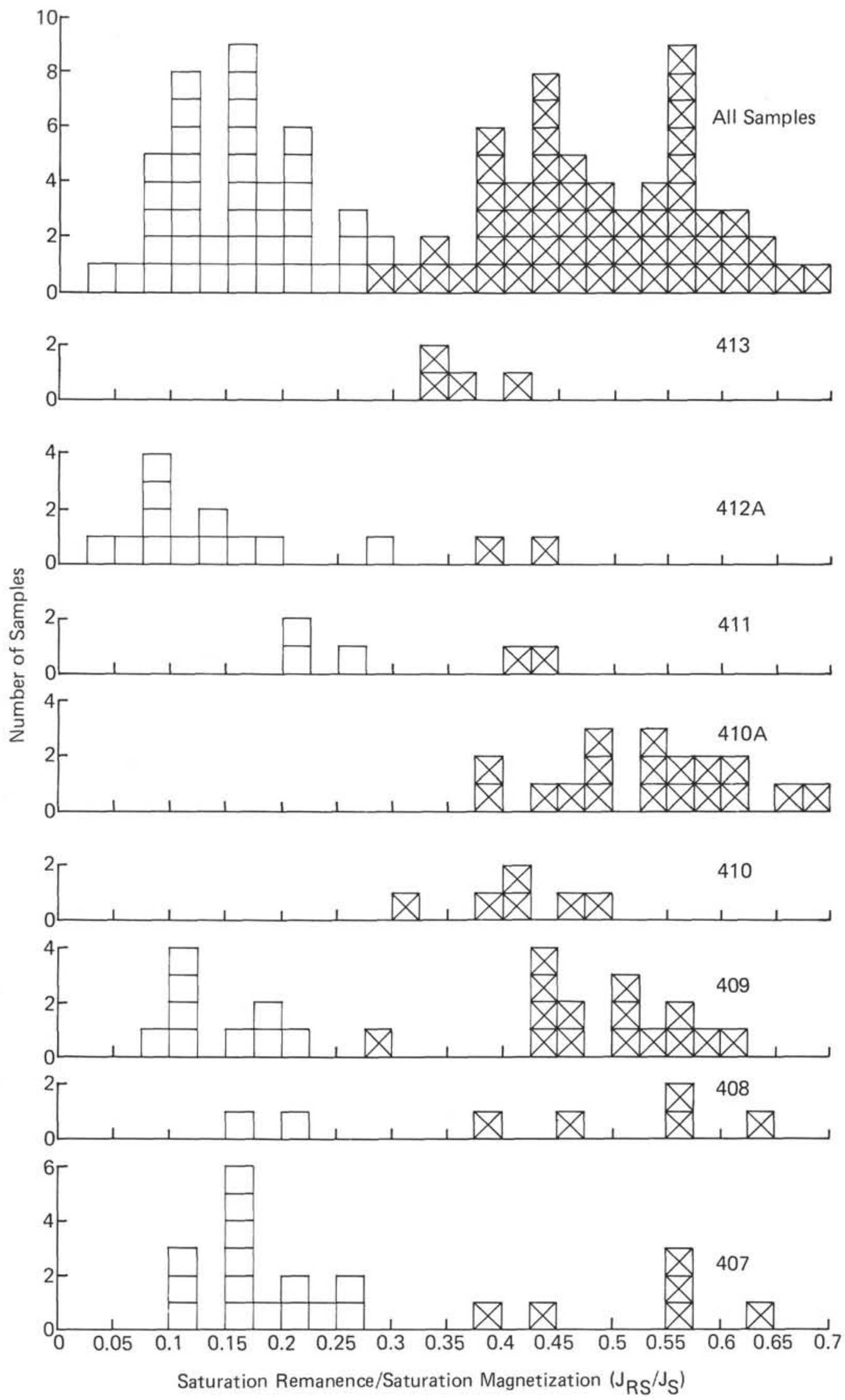

Figure 2. Histograms showing the variation of $J_{R S} / J_{S}$ in Holes 407 through 413. X indicates samples with a coercive force greater than 100 Oe (see text). 

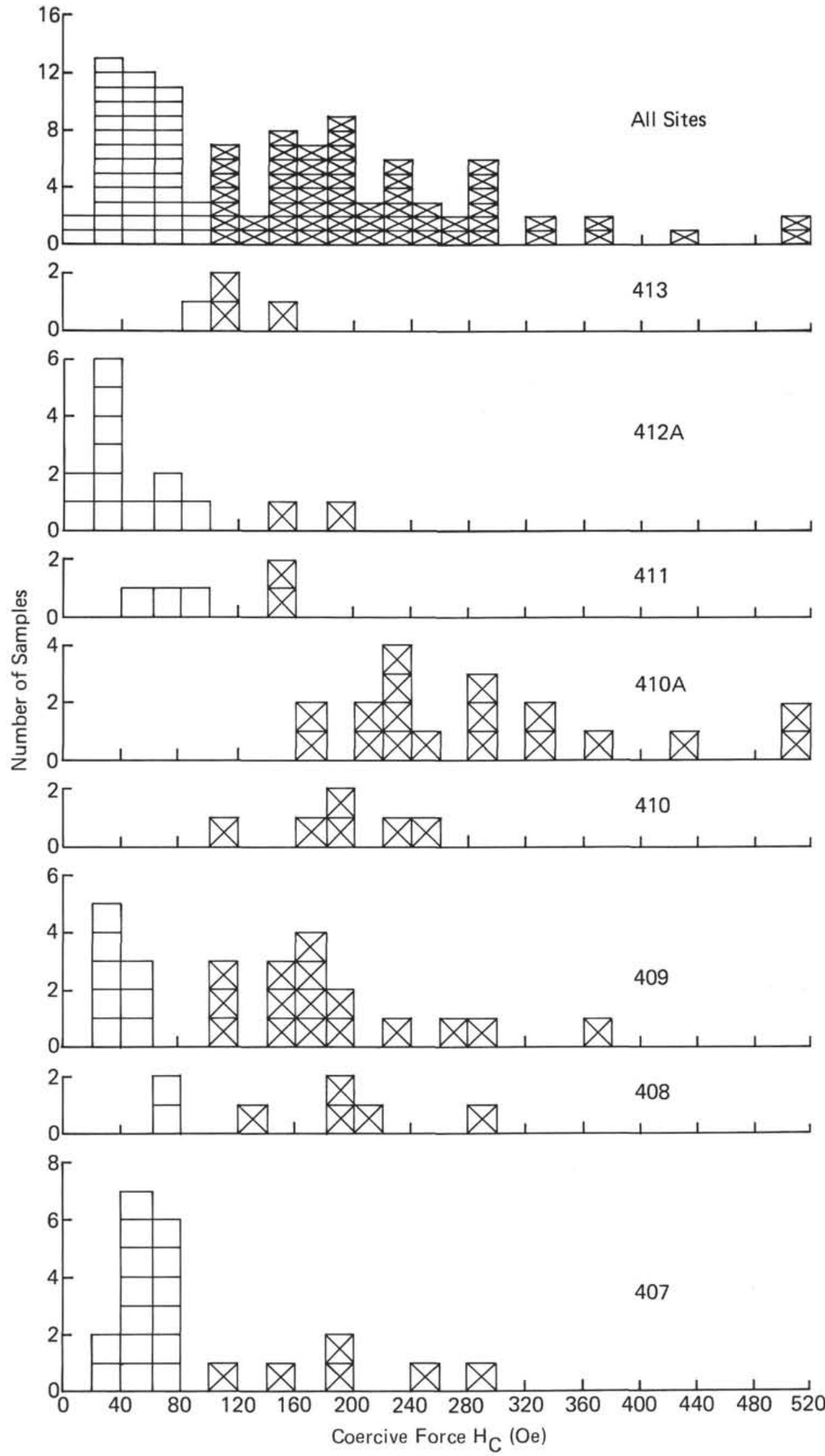

Figure 3. Histograms showing the variation of $\mathrm{H}_{C}$ in Holes 407 through 413. X indicates samples with a coercive force greater than 100 Oe (see text). 


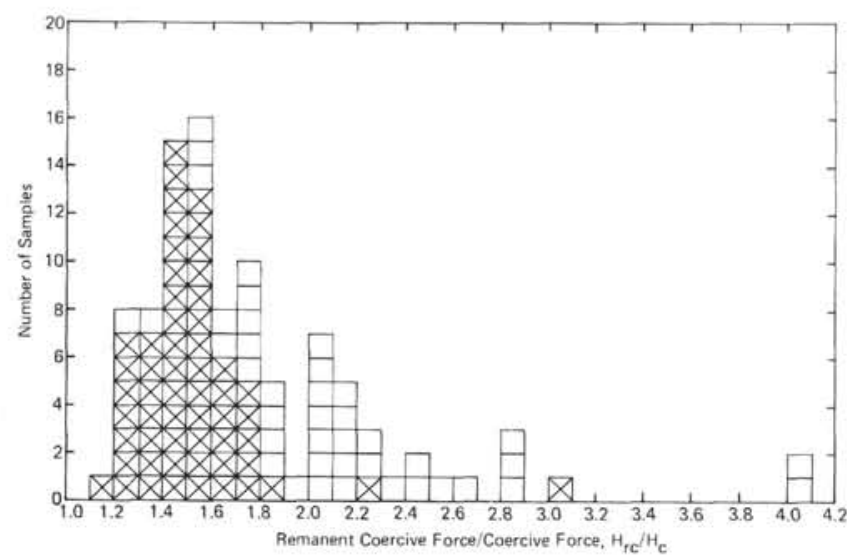

Figure 4. Histogram showing the variation of $H_{R C} / H_{C}$ in Holes 407 through 413. $X$ indicates samples with a coercive force greater than $100 \mathrm{Oe}$ (see text).

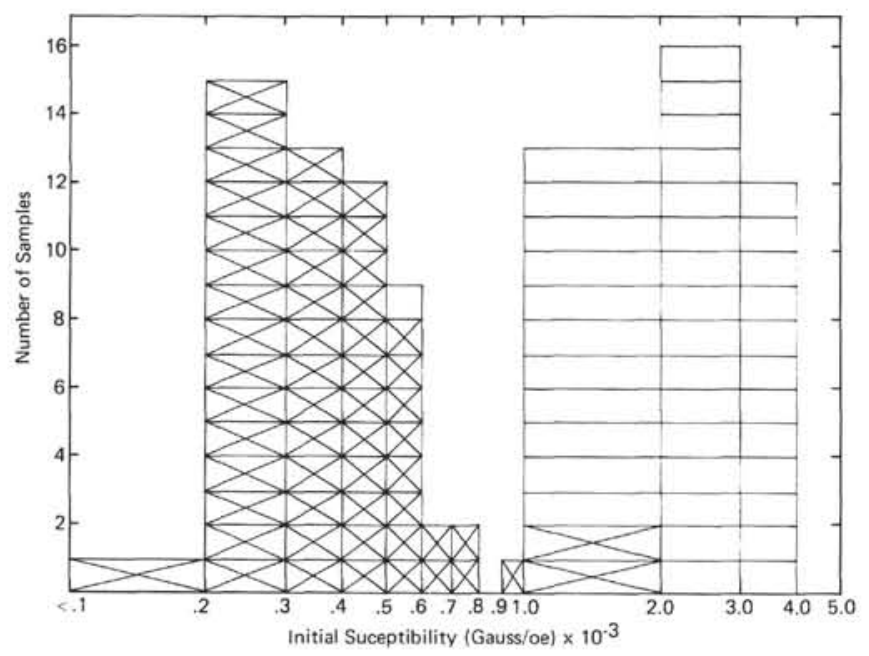

Figure 5. Histogram showing the variation of $\chi$ in Holes 407 through 413. $X$ indicates samples with a coercive force greater than $100 \mathrm{Oe}$ (see text). A logarithmic scale has been used for convenience along the abscissa.

magnetically hard. If we associate the reversible thermomagnetic curves with stoichiometric titanomagnetites and slightly oxidized titanomaghemites $(\mathrm{Z} \leqq 0.5$, using Readman and O'Reilly's calibration diagrams [see for example Hall and Ryall, 1977]), and irreversible curves with the more strongly oxidized titanomaghemites, it is apparent that there is a relationship between oxidation state and the magnetic properties; i.e., the more oxidized samples are much harder magnetically. Dunlop and Hale (1977) reached the same conclusion from measurements on Leg 37 basalts. Following their notation, we will refer to the samples with reversible thermomagnetic curves as type I, and those with irreversible curves as type II. The grain size estimates from the opaque work (shown in Table 2) indicate that the type I samples, in general, contain larger grains than type II samples. This is certainly so in Holes 410A and $412 \mathrm{~A}$ (see Kobayashi et al., this volume).

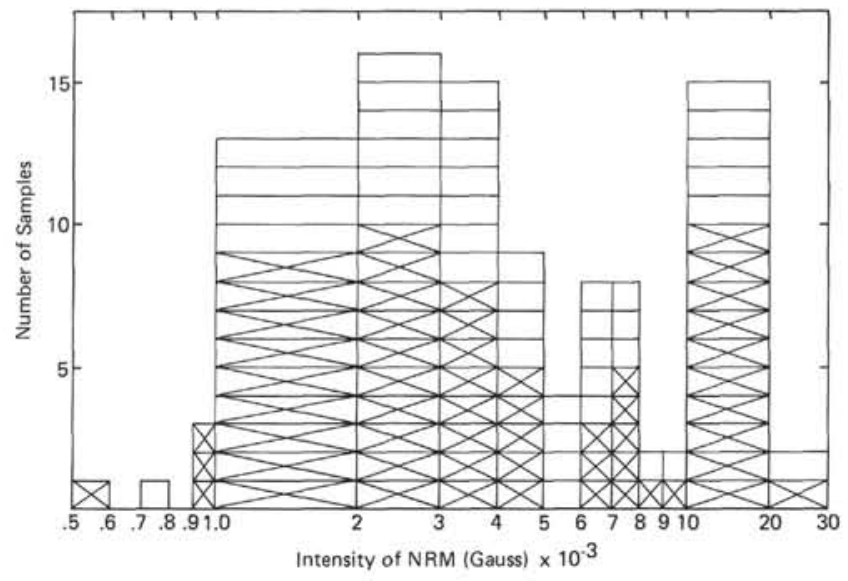

Figure 6. Histogram showing the variation of $J_{N}$ in Holes 407 through 413. $X$ indicates samples with a coercive force greater than $100 \mathrm{Oe}$ (see text). A logarithmic scale has been used for convenience along the abscissa.

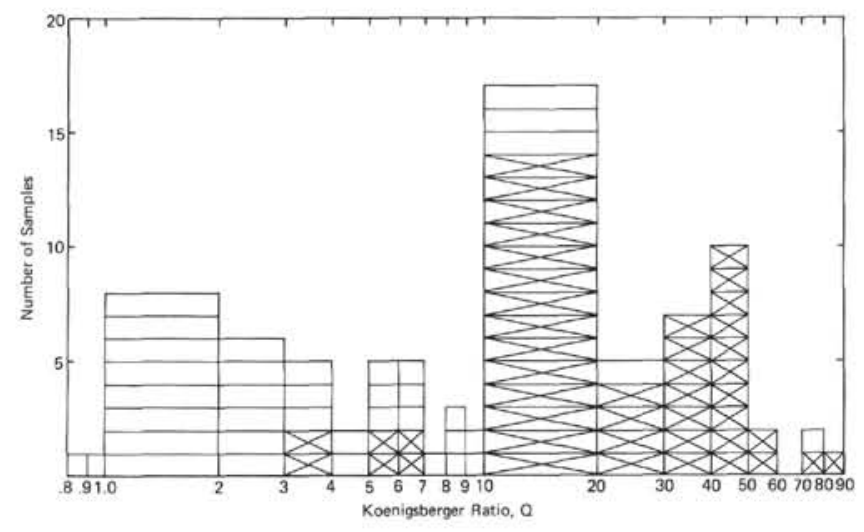

Figure 7. Histogram showing the variation of $Q$ in Holes 407 through 413. $X$ indicates samples with a coercive force greater than $100 \mathrm{Oe}$ (see text). A logarithmic scale has been used for convenience along the abscissa.

Table 2 contains three samples (marked with double asterisks) whose properties do not fit the above pattern. Sample 409-24-1, 142-148 cm is discussed in detail in the next chapter (Kobayashi et al., this volume), and is thought to be an andesite that contains magnetite. Sample 407-39-3, $42-44 \mathrm{~cm}$ has an irreversible thermomagnetic curve but a low Curie temperature $\left(200^{\circ} \mathrm{C}\right)$, and magnetic properties closer to the type I samples. It is possible that in this case the irreversibility may be the result of thermal lag in the magnetic balance. In Sample 410A-2-5, $12 \mathrm{~cm}$, there is a contact present, and the magnetic properties indicate a mixture. Also, the two Curie temperatures listed come from two distinctly different parts of this sample (see next chapter). We therefore feel justified in excluding these samples from our discussion.

In Table 3, we show the mean values of the magnetic properties of type I and type II samples. This table shows clearly the differences between the two types of behavior, as does Figure 8 when we distinguish between the two types. 


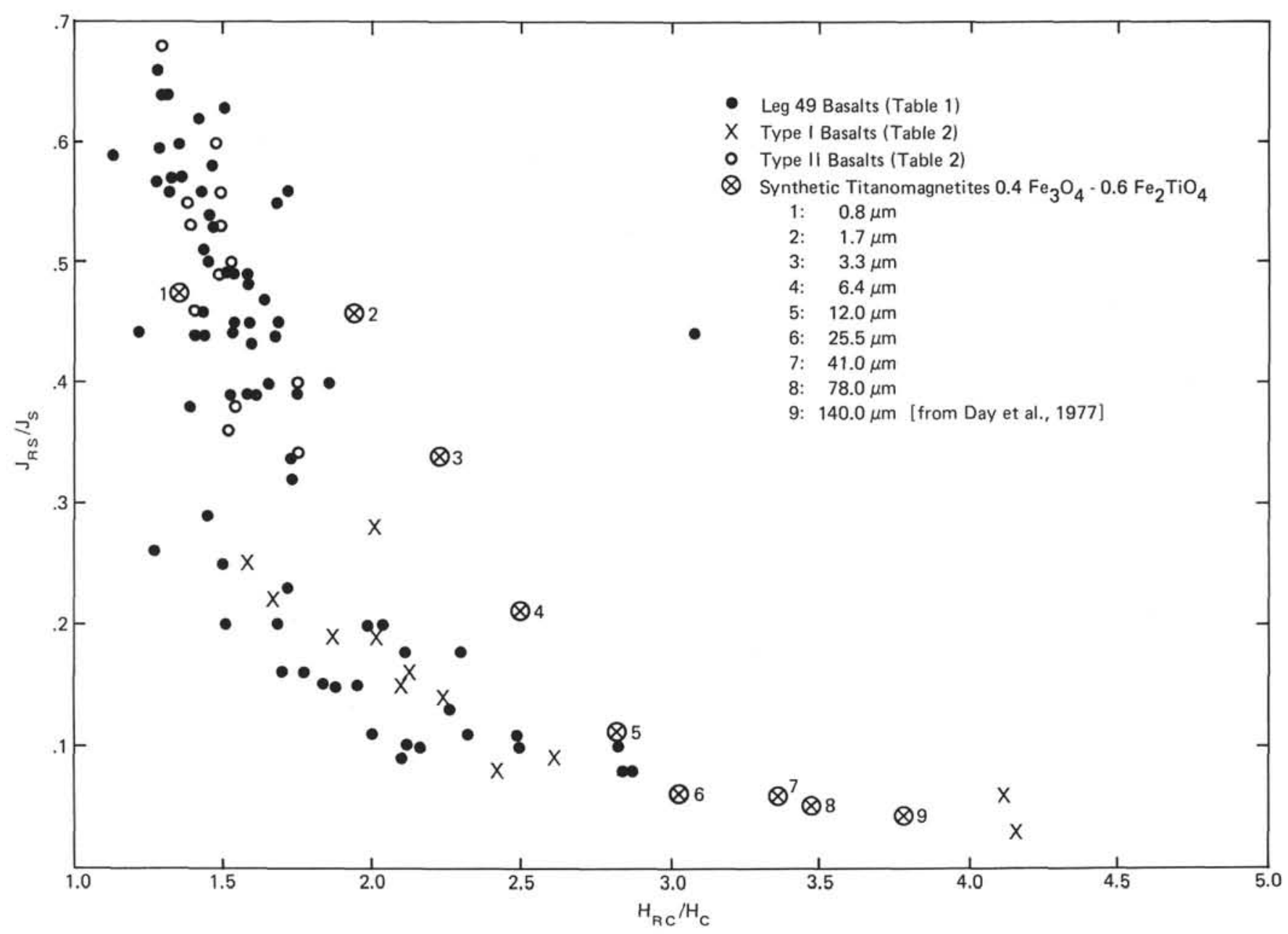

Figure 8. Plot showing the relationship between $J_{R S} / J_{S}$ and $H_{R C} / H_{C}$ for all DSDP Leg 49 basalts.

Further, Figure 8 suggests that the type II samples contain finer grains, which is consistent with the visual observations. It is not obvious why type II samples should contain the finer grains. Is it because the finer grains are preferentially oxidized, or does the oxidation process reduce the grain size? One would intuitively think the former, but Johnston and Hall (in press) have suggested that the cracking found in oxidized grains is shrinkage cracking caused by reduction of volume. Further, the cracks could act to reduce the grain size. This has been taken into account whenever possible in the visual estimates of grain size. We feel, however, that this ambiguity cannot be resolved with the present data.

It is disturbing to find that whereas the magnetic properties are different for type I and type II samples, the intensity of NRM does not change significantly (see Table 3 ). We offer no explanation for this observation at this time.

After examining the measured magnetic properties (Tables 2 and 3 ), we decided that we could use a coercive force of $100 \mathrm{Oe}$ as a method of dividing the whole data set (99 samples) into two types. When this is done, as we have shown in Figures 1 through 6, we see that the whole data set can be interpreted in the same general way that we have interpreted the 28 samples whose Curie temperatures are known. Unfortunately, a model for the variation of magnetic properties with oxidation must await further, more detailed, investigations.

\section{CONCLUSIONS}

The magnetic properties of 99 DSDP Leg 49 basalts show a great variability, not only between sites, but also within each site. These variations, however, are not systematic with age, depth or location (see Steiner et al., this volume). The 99 samples can be divided into two distinct types with markedly differing magnetic properties. Thermomagnetic measurements on 28 of these samples indicate that our division into two groups is exactly the same as that found by previous workers using the criterion of reversibility of thermomagnetic curves. In the absence of a complete explanation for the differences between the two types, we can summarize our observations as follows:

1) Highly oxidized samples (type II) contain mainly SD and PSD grains. They exhibit large coercivities $(\mathrm{Hc}>100$ $\mathrm{Oe}$ ), a high $\mathrm{J}_{\mathrm{RS}} / \mathrm{Js}_{\mathrm{s}}$ value, low $\mathrm{HRC}_{\mathrm{RC}} / \mathrm{Hc}$ ratio, and low susceptibility.

2) Slightly oxidized samples (type I) contain large PSD grains and MD grains. They are magnetically soft (coercive force less than $100 \mathrm{Oe}$, high susceptibility, low $\mathrm{JRS}_{\mathrm{RS}} / \mathrm{Js}_{\mathrm{s}}$ ). 
TABLE 2

Thermomagnetic and Magnetic Properties of Selected DSDP Leg 49 Basalts

\begin{tabular}{|c|c|c|c|c|c|c|c|c|c|c|c|}
\hline $\begin{array}{c}\text { Sample } \\
\text { (Interval in } \mathrm{cm} \text { ) }\end{array}$ & $\mathrm{T}_{\mathrm{C}}{ }^{(\mathrm{a})}$ & $\mathrm{J}_{S}{ }^{(\mathrm{b})}$ & ${ }^{\mathrm{J} / \mathrm{J}_{\mathrm{S}}}$ & $\mathrm{H}_{\mathrm{C}}{ }^{(\mathrm{c})}$ & $\mathrm{H}_{\mathrm{RC}}{ }^{(\mathrm{d})}$ & $\mathrm{H}_{\mathrm{RC} / \mathrm{H}_{\mathrm{C}}}$ & $x^{(e)}$ & $\mathrm{J}_{\mathrm{RS}}{ }^{(\mathrm{f})}$ & $\mathrm{J}_{\mathrm{N}}{ }^{(\mathrm{g})}$ & $\mathrm{Q}^{(\mathrm{h})}$ & Grain Size ${ }^{(i)}$ \\
\hline \multicolumn{12}{|l|}{ Reversible group } \\
\hline $407-39-3,25-27$ & 170 & 3.04 & 0.16 & 46 & 98 & 2.13 & 2.94 & 0.487 & 4.40 & 2.9 & - \\
\hline $407-47-3,64-68$ & 195 & 3.06 & 0.19 & 62 & 116 & 1.87 & 2.51 & 0.581 & 12.9 & 9.9 & - \\
\hline $409-10-1,10-12$ & 143 & 1.79 & 0.09 & 28 & 73 & 2.61 & 3.13 & 0.163 & 2.20 & 1.4 & $>10$ \\
\hline $409-24-1,142-148 * *$ & 540 & 4.16 & 0.18 & 107 & 245 & 2.29 & 4.45 & 0.748 & 12.2 & 5.3 & $5-10$ \\
\hline $411-1-1,78-81$ & 230 & 1.08 & 0.22 & 67 & 113 & 1.67 & 1.23 & 0.238 & 3.83 & 6.9 & $2-5$ \\
\hline $411-2-2,6-9$ & 205 & 1.15 & 0.25 & 87 & 138 & 1.59 & 1.10 & 0.287 & 6.78 & 14 & $1-4$ \\
\hline $412 \mathrm{~A}-1-1,29-30$ & 170 & 1.66 & 0.14 & 38 & 85 & 2.24 & - & 0.232 & 7.99 & - & $7-15$ \\
\hline $412 \mathrm{~A}-2-2,35-37$ & 178 & 1.84 & 0.08 & 31 & 75 & 2.42 & 2.36 & 0.147 & 1.99 & 1.9 & $10-40$ \\
\hline $412 \mathrm{~A}-7-2,60-62$ & 270 & 2.16 & 0.19 & 90 & 182 & 2.02 & 1.31 & 0.410 & 3.28 & 5.6 & $2-15$ \\
\hline $412 \mathrm{~A}-9-1,48-50$ & 205 & 1.4 & 0.28 & 65 & 131 & 2.01 & 1.48 & 0.392 & 5.88 & 8.8 & - \\
\hline $412 \mathrm{~A}-11-3,69-71$ & 210 & 1.76 & 0.15 & 55 & 115 & 2.10 & 1.88 & 0.264 & 3.72 & 4.4 & $0.5-5$ \\
\hline $412 \mathrm{~A}-14-2,99-101$ & 185 & 1.82 & 0.06 & 17 & 70 & 4.12 & - & 0.109 & 1.95 & - & - \\
\hline $412 \mathrm{~A}-14-5,30-32$ & 200 & 3.70 & 0.03 & 18 & 75 & 4.17 & 2.12 & 0.111 & 0.79 & 0.83 & - \\
\hline \multicolumn{12}{|l|}{ Irreversible group } \\
\hline $407-39-3,42-44 \quad * *$ & 200 & 2.71 & 0.20 & 62 & 124 & 2.0 & 1.65 & 0.540 & 2.60 & 3.0 & - \\
\hline $407-47-1,116-118$ & 315 & 0.285 & 0.56 & 183 & 271 & 1.48 & 0.261 & 0.160 & 1.47 & 10.8 & - \\
\hline $407-47-2,88-90$ & 273 & 0.458 & 0.55 & 287 & 393 & 1.37 & 0.240 & 0.252 & 1.30 & 10.4 & - \\
\hline $409-22-1,53-57$ & 208 & 0.662 & 0.50 & 160 & 243 & 1.52 & 0.410 & 0.281 & 3.10 & 15 & - \\
\hline $410-39-1,76-78$ & 265 & 0.720 & 0.46 & 225 & 316 & 1.40 & 0.361 & 0.329 & 4.50 & 27 & $.5-3$ \\
\hline $410 \mathrm{~A}-1-7,21-24$ & 305 & 0.463 & 0.60 & 422 & 622 & 1.47 & 0.225 & 0.278 & 2.35 & 22 & -25 \\
\hline $410 A-2-5,12 \quad * *$ & $200 / 300$ & 0.284 & 0.44 & 211 & 650 & 3.08 & 0.531 & 0.125 & - & - & - \\
\hline $410 \mathrm{~A}-3-2,111-113$ & 310 & 0.379 & 0.53 & 281 & 412 & 1.47 & 0.205 & 0.201 & 1.67 & 17 & $.5-3$ \\
\hline $410 \mathrm{~A}-4-2,87-93$ & 275 & 0.829 & 0.38 & 169 & 260 & 1.54 & 0.529 & 0.315 & 3.63 & 15 & $.5-5$ \\
\hline $410 \mathrm{~A}-5-1,69-76$ & 315 & 0.623 & 0.53 & 295 & 408 & 1.38 & 0.344 & 0.330 & 6.47 & 40 & $<0.25-3$ \\
\hline $410 \mathrm{~A}-5-4,95-96$ & 300 & 0.599 & 0.68 & 506 & 655 & 1.29 & 0.293 & 0.407 & 7.99 & 88 & $<0.25-2$ \\
\hline $410 \mathrm{~A}-6-1,8-16$ & 405 & 0.482 & 0.49 & 239 & 356 & 1.49 & 0.353 & 0.236 & 2.66 & 16 & $<0.25$ \\
\hline $411-5-1,21-23$ & 250 & 1.21 & 0.40 & 141 & 247 & 1.75 & 0.344 & 0.486 & 1.82 & 11.8 & $1-4$ \\
\hline $413-1-2,64-67$ & 250 & 0.89 & 0.36 & 110 & 166 & 1.51 & 0.44 & 0.319 & 7.9 & 40 & $2-5$ \\
\hline $413-1-2,100$ & 245 & 1.216 & 0.34 & 113 & 195 & 1.73 & 0.626 & 0.410 & 12.3 & 44 & - \\
\hline
\end{tabular}

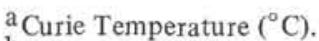

$\mathrm{b}_{\text {Saturation Magnetization (Gauss). }}$

${ }^{c}$ Coercive Force (Oe).

$\mathrm{d}_{\text {Remanent Coercive Force (Oe). }}$.

Initial Susceptibility ( $\times 10^{-3}$ Gauss Oe).

$\mathrm{f}_{\text {Saturation Remanence (Gauss). }}$

${ }^{\mathrm{g}}$ Intensity of Natural Remanent Magnetization ( $\times 10^{-3}$ Gauss).

$\mathrm{h}_{\text {Koenigsberger Ratio. }}$

${ }^{\mathrm{i}}$ Visual Estimates of Grain Size (microns).

3) Saturation magnetization decreases by a factor of about 3 on oxidation.

4) The Koenigsberger ratio, Q, is much larger for type II samples.

5) There is no significant difference in mean intensity of NRM for the type I and type II samples.

6) The type II samples generally contain finer opaque grains than type 1 samples.

We have thus extended our knowledge of the magnetic behavior in submarine basalts to show that, in addition to two types of thermomagetic behavior, we have two distinct types of magnetic behavior. The reasons for the occurrence of these different magnetic types must be discovered before we can fully understand the magnetization of the oceanic crust.

\section{ACKNOWLEDGMENTS}

We would first like to thank the many people who were responsible for the success of DSDP Leg 49. Second, we are indebted to Susan Green and Karin Schultz for their help with many of the spinner measurements. Finally, two of us (R. D. and S. H.) would like to thank Professor Michael Fuller for allowing us the freedom to pursue this project.

\section{REFERENCES}

Day, R., Fuller, M., and Schmidt, V. A., 1977. Hysteresis properties of titanomagnetites: Grain size and composition dependence, Phys. Earth Planet. Int., v. 13, p. 260.

Dunlop, D. J. and Hale, C. J., 1977. Simulation of long-term changes in the magnetic signal of the oceanic crust, Canadian J. Earth Sci., v. 14, p. 716.

Fuller, M., 1967. The a.c. bridge method. In Collinson, D. W., Creer, K. M., and Runcorn, S. K. (Eds.), Methods in paleomagnetism; New York (Elsevier).

Hall, J. M. and Ryall, P. J. C., 1977. Rock magnetism of basement rocks. In Aumento, F., Melson, W. G., et al., Initial Reports of the Deep Sea Drilling Project, v. 37: Washington (U.S. Government Printing Office), p. 489.

Johnston, H. P., 1978. Opaque mineralogy of the igneous rock samples from Hole 395A-DSDP Leg 45. In Melson, W. G., Rabinowitz, P. D., et al., Initial Reports of the Deep Sea 
TABLE 3

Mean Values of the Magnetic Properties Listed in Table 2

\begin{tabular}{|c|c|c|c|c|c|c|c|c|c|c|}
\hline & $\mathrm{T}_{\mathrm{C}}{ }^{(\mathrm{a})}$ & $\mathrm{J}_{\mathrm{S}}{ }^{(\mathrm{b})}$ & ${ }^{\mathrm{J}} \mathrm{JJ}_{\mathrm{S}}$ & $\mathrm{H}_{\mathrm{C}}{ }^{(\mathrm{c})}$ & $\mathrm{H}_{\mathrm{RC}}{ }^{(\mathrm{d})}$ & $\mathrm{H}_{\mathrm{RC} / \mathrm{H}_{\mathrm{C}}}$ & $x^{(e)}$ & $\mathrm{J}_{\mathrm{RS}}{ }^{(\mathrm{f})}$ & $\mathrm{J}_{N}^{(\mathrm{g})}$ & $\mathrm{Q}^{(\mathrm{h})}$ \\
\hline \multicolumn{11}{|c|}{ Reversible (type I) } \\
\hline $\begin{array}{l}\text { Mean } \\
\text { Minimum }\end{array}$ & $\begin{array}{l}197 \\
143\end{array}$ & $\begin{array}{l}2.04 \\
1,08\end{array}$ & $\begin{array}{l}0.15 \\
0.03\end{array}$ & $\begin{array}{l}50 \\
17\end{array}$ & $\begin{array}{r}106 \\
70\end{array}$ & $\begin{array}{l}2.41 \\
1.59\end{array}$ & $\begin{array}{l}2.01 \\
1.1\end{array}$ & $\begin{array}{l}0.285 \\
0.109\end{array}$ & $\begin{array}{l}4.29 \\
0.79\end{array}$ & $\begin{array}{l}5.7 \\
0.83\end{array}$ \\
\hline Maximum & 270 & 3.70 & 0.28 & 90 & 182 & 4.17 & 3.13 & 0.748 & 12.9 & 14.3 \\
\hline $\begin{array}{l}\text { Mean } \\
\text { Minimum } \\
\text { Maximum }\end{array}$ & $\begin{array}{l}197 \\
143 \\
270\end{array}$ & $\begin{array}{l}2.04 \\
1.08 \\
3.70\end{array}$ & $\begin{array}{l}0.15 \\
0.03 \\
0.28\end{array}$ & $\begin{array}{l}50 \\
17 \\
90\end{array}$ & $\begin{array}{r}106 \\
70 \\
182\end{array}$ & $\begin{array}{l}2.41 \\
1.59 \\
4.17\end{array}$ & $\begin{array}{l}2.01 \\
1.1 \\
3.13\end{array}$ & $\begin{array}{l}0.285 \\
0.109 \\
0.748\end{array}$ & $\begin{array}{c}4.29 \\
0.79 \\
12.9\end{array}$ & $\begin{array}{c}5.7 \\
0.83 \\
14.3\end{array}$ \\
\hline \multicolumn{11}{|c|}{ Irreversible (type II) } \\
\hline $\begin{array}{l}\text { Mean } \\
\text { Minimum } \\
\text { Maximum }\end{array}$ & $\begin{array}{l}286 \\
208 \\
405\end{array}$ & $\begin{array}{l}0.678 \\
0.284 \\
1.22\end{array}$ & $\begin{array}{l}0.49 \\
0.34 \\
0.68\end{array}$ & $\begin{array}{l}241 \\
110 \\
506\end{array}$ & $\begin{array}{l}350 \\
166 \\
655\end{array}$ & $\begin{array}{l}1.49 \\
1.29 \\
1.75\end{array}$ & $\begin{array}{l}0.348 \\
0.193 \\
0.616\end{array}$ & $\begin{array}{l}0.305 \\
0.160 \\
0.540\end{array}$ & $\begin{array}{c}4.4 \\
1.30 \\
12.3\end{array}$ & $\begin{array}{l}27.5 \\
10.4 \\
88.0\end{array}$ \\
\hline
\end{tabular}

${ }^{\text {a }}$ Curie Temperature $\left({ }^{\circ} \mathrm{C}\right)$.

$\mathrm{b}_{\text {Saturation Magnetization (Gauss). }}$

${ }^{c}$ Coercive Force (Oe).

$\mathrm{d}_{\text {Remanent Coercive Force (Oe) }}$

Initial Susceptibility ( $\times 10^{-3}$ Gauss $\mathrm{Oe}^{-1}$ ).

${ }^{f}$ Saturation Remanence (Gauss).

$\mathrm{g}_{\text {Intensity of Natural Remanent Magnetization ( }} 10^{-3}$ Gauss).

$\mathrm{h}_{\text {Koenigsberger Ratio. }}$

Drilling Project, v. 45: Washington (U.S. Government Printing Office).

Johnston, H. P. and Hall, J. M., in press. A detailed rock magnetic and opaque mineralogy study of the basalts from the Nazca Plate, Geophys. J. Roy. Astr. Soc.

Kobayashi, K, and Fuller, M., 1967. Vibration magnetometer. In Collinson, D. W., Creer, K. M., and Runcorn, S. K. (Eds.), Methods in paleomagnetism: New York (Elsevier).
Parry, L. G., 1965. Magnetic properties of dispersed magnetic powders, Phil. Mag., v. 11, p. 303.

Readman, P. W. and O'Reilly, W., 1972. Magnetic properties of oxidized (cation deficient) titanomagnetites $\left(\mathrm{Fe}, \mathrm{Ti}\right.$, ㅁ) ${ }_{3} \mathrm{O}_{4}, J$. Geomag. Geoelect., v. 24 , p. 69.

Stoner, E. C. and Wohlfarth, E. P., 1948. A mechanism of magnetic hysteresis in heterogeneous alloys, Phil. Trans. Roy. Soc. London, v. A240, p. 599. 